\section{Hydration Efficiency of Traditional and Alternative Greenhouse Substrate Components}

\author{
Jeb S. Fields ${ }^{1}$, William C. Fonteno ${ }^{2}$, and Brian E. Jackson ${ }^{3,4}$ \\ North Carolina State University, Department of Horticultural Science, 130 \\ Kilgore Hall, Campus Box 7609, Raleigh, NC 27607
}

Additional index words. coconut coir, initial moisture content, peatmoss, perlite, pine bark, pine tree substrate, preferential flow, wettability, wetting agent

\begin{abstract}
Wettability is a major factor in determining whether a material can be effectively and efficiently used as a component in greenhouse substrates. Poor wettability can lead to poor plant growth and development as well as water use inefficiency. This research was designed to test the wettability and hydration efficiency of both traditional and alternative components of substrates under different initial moisture contents (MCs) and wetting agent levels. Peatmoss, perlite, coconut coir, pine bark, and two differently manufactured pine tree substrate components (pine wood chips and shredded pine wood) were tested at $50 \%$ and $25 \%$ initial MC (by weight). The objective of this research was to determine the effects of initial MC and wetting agent rates on the wettability and hydration efficiency of these substrate components. Each component received four wetting agent treatments: high $\left(348 \mathrm{~mL} \cdot \mathrm{m}^{-3}\right)$, medium $\left(232 \mathrm{~mL} \cdot \mathrm{m}^{-3}\right)$, low $\left(116 \mathrm{~mL} \cdot \mathrm{m}^{-3}\right)$, and none $\left(0 \mathrm{~mL} \cdot \mathrm{m}^{-3}\right)$. Hydration efficiency was influenced by initial $\mathrm{MC}$, wetting agent rate, and inherent hydrophobic properties of the materials. Wetting agents did increase the hydration efficiencies of the substrate components, although not always enough to overcome all cases of hydrophobicity.
\end{abstract}

Wettability of a material was defined by Letey et al. (1962) as the ability of a liquid to spread over a material's surface. In substrates, proper wettability ensures a more even distribution of water (and nutrients) throughout the root environment. Appropriate wettability also improves water-holding capacity, which has been shown to increase plant growth (Plaut et al., 1973). Horticultural substrates often have wettability issues resulting from the nature and high volume of organic matter (OM) components in them. These components, primarily composed of sphagnum peatmoss and pine bark, can become hydrophobic, thus reducing wettability (Dekker et al., 2000a; Michel et al., 2001). The molecules of OM contain many organic acid functional groups on their exterior surfaces, like carboxylic acids and phenolic acids, among others. These acidic functional groups tend to repel water from the particle surfaces when in a balanced state with hydrogen cations bound to oxygen anions (Ellerbrock et al., 2005). As substrates dry, hydrophobicity can intensify, complicating the wetting and rewetting process during plant production (Valat et al., 1991). Thus, many organic substrates can develop

\footnotetext{
Received for publication 11 Oct. 2013. Accepted for publication 23 Jan. 2014.

This paper is a portion of a thesis submitted by Jeb $\mathrm{S}$. Fields as required to fulfill degree requirements. ${ }^{1}$ Graduate Student.

${ }^{2}$ Professor.

${ }^{3}$ Assistant Professor.

${ }^{4}$ To whom reprint requests should be addressed; e-mail Brian_Jackson@ncsu.edu.
}

bonds and spread out more evenly over the surface of a substrate. Wetting agents, like all surfactants, are chemically composed of two parts, a hydrophilic hydrocarbon tail and a hydrophobic lipid head. The hydrophobic end will adhere to the surface of the substrate particle leaving the hydrophilic end exposed. The water molecules will then bind to the hydrophilic end and spread out across the surface of the particle. This reduces surface energy of the solid particle and promotes a more uniform distribution of water over the surface. Wetting agents are commonly used in many substrates to achieve proper hydration with fewer irrigation events after potting.

Hydration efficiency was defined in this study as the ability of a material to capture and retain water in the fewest number of hydration events (water applications). The objectives of this study were: 1) to characterize the wettability of traditional substrate components and compare them with two newer pine tree substrate components; and 2) to determine hydration efficiency of these components.

\section{Materials and Methods}

Substrate components. Substrate components tested were coconut coir (Densu Coir, Ontario, Canada), sphagnum peatmoss (Premier Tech, Canada), aged pine bark, perlite, and two types of hammermilled loblolly pine wood (Pinus taeda L.). To create the pine tree substrate components, fresh loblolly pine wood was hammermilled through a $6.35-\mathrm{mm}$ screen after delimbed pine logs were initially processed through either a wood chipper or a wood shredder. Pine trees processed in the two different types of machinery produce completely different pine tree substrate components even when milled through the same hammermill screen size (Jackson and Fonteno, 2013). The pine logs for chipping were harvested on 9 Dec. 2011 and passed through a DR Chipper (Model 356447; 18 HP DR Power Equipment, Vergennes, VT) on 3 Jan. 2012 and hammermilled (Meadows Mills, North Wilkersboro, NC) on 5 Jan. 2012. The pine logs for shredding were harvested on 12 Dec. 2011 and shredded in a Wood Hog shredder (Morbark ${ }^{\odot}$, Winn, MI) on 9 Jan. 2012. The shredded pine wood (SPW) was then hammermilled as previously described for the pine wood chips (PWC) on 10 Jan. 2012.

All processed wood materials were then placed in $55-\mathrm{L}$ poly bags and stored indoors at $22^{\circ} \mathrm{C}$ until needed for further testing. Care was taken to monitor the bags to prevent extra drying or increased temperatures. Because of the small sample sizes and storage conditions, the materials did not dry out nor display any increased temperatures as are possible with organic materials. All materials were tested over an 8-week period after tree harvesting and processing (hammermilling) during which time wood materials were stored in bulk bags/ totes under shelter.

Particle size distribution of 150 -g ovendried substrate samples was determined on three replications of each substrate component with 11 sieves (ranging from greater than 
$6.3 \mathrm{~mm}$ to less than $0.063 \mathrm{~mm}$ ) plus a bottom pan. Sieves and pan were shaken for 5 min with a RX-29 Ro-Tap sieve shaker (278 oscillations/min, 150 taps/min; W.S. Tyler, Mentor, $\mathrm{OH}$ ) and the particle fractions retained on each sieve and the amount that passed through the smallest sieve and retained by the sieve pan were weighed.

Moisture content and wetting agent treatments. Each of the six components were hydrated to an initial moisture content (IM) of $50 \%$ by weight. Each component was separated into four subsamples of equal volume (4 L). Each subsample was treated with AquaGro ${ }^{\circledR}$-L (Aquatrols, Paulsboro, NJ) WA at 0 (none), 116 (low rate), 232 (medium rate), and 348 (high rate) $\mathrm{mL} \cdot \mathrm{m}^{-3}$, respectively. The amount of WA required to achieve the four testing levels for each sample was premixed with the water required to bring the sample to $50 \%$ IM. The amount of water required to bring each substrate up to $50 \%$ IM and the amount of WA required for each respective subsample were mixed in a 4-L SureSpray ${ }^{\mathrm{TM}}$ sprayer (Model 20010; Chapin, Batavia, NY). Substrate components were individually spread out at a depth of $1 \mathrm{~cm}$ on a metal tray, and the WA/water mixture was evenly applied (sprayed from sprayer). The solution was thoroughly mixed in each component immediately after application by turning and mixing until the entirety of the solution had been applied. Substrate components were also tested at 25\% MC. To do this, half of each treatment was spread on a tray and allowed to air-dry until 25\% MC was attained. Once attained, samples were sealed in plastic bags to prevent further water loss while also allowing for moisture equilibrium. There were a total of 48 treatments in this study (six components $\times$ four WA levels $\times$ two initial MCs).

Hydration efficiency measurements. This experiment was conducted following the procedures first described by Fonteno et al. (2013) and displayed in Figure 1. The equipment consisted of a transparent cylinder, $5 \mathrm{~cm}$ i.d. $\times 15 \mathrm{~cm} \cdot \mathrm{h}^{-1}$, with a mesh screen (mesh size $18 \times 16$; New York Wire, York, PA), attached to one end, using rubber pressure plate rings (Soilmoisture Equipment Corp., Santa Barbara, CA); a 250-mL separatory funnel; a 250-mL beaker; and a $10-\mathrm{mL}$ plastic vial $(4 \mathrm{~cm}$ diameter), referred to in this work as a "diffuser." The diffuser had five evenly spaced holes in the bottom (2.38 $\mathrm{mm}$ diameter), which enabled it to diffuse the force of water as it is

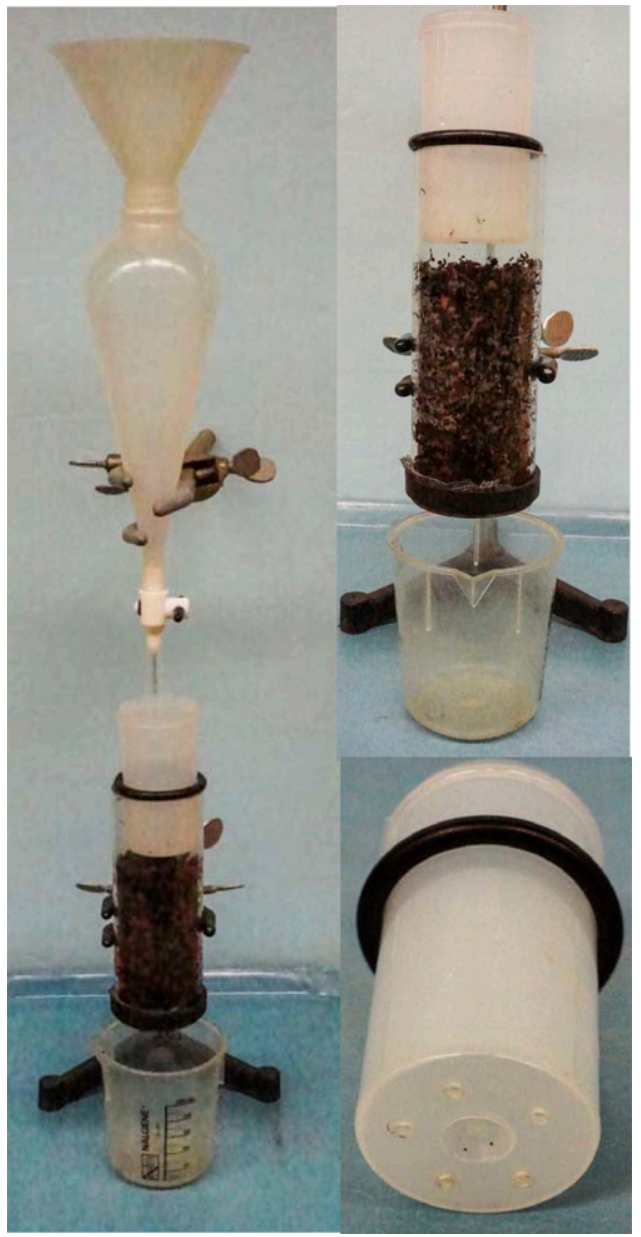

Fig. 1. Hydration efficiency apparatus. (Left, top to bottom) Funnel, separatory funnel with stopcock, water flow diffuser, sample cylinder, beaker. (Top right) Close-up of water diffuser with O-ring above the sample cylinder allowing control of hydraulic head. (Bottom right) Water diffuser with O-ring and five holes in the bottom.

released and falls to the surface of the substrate (Fig. 1). As water moves from the funnel into the diffuser, it slowly drips out of the five holes onto the substrate surface with force similar to a drip irrigation system in a greenhouse production setting. A rubber O-ring is placed around the outside of the diffuser, which allowed it to sit at an adjustable height atop the transparent cylinder.

The transparent cylinders were packed with each substrate component to achieve a bulk density within $5 \%$ of other samples of the same components. To do this, cylinders were filled with substrate and gently packed by holding filled cylinders $10 \mathrm{~cm}$ off a flat surface and tapping three times so the height of the sample in the cylinder was $10 \mathrm{~cm}$, which equated to $200 \mathrm{~mL}$ of substrate. Four replications were produced for each of the 48 treatments, totaling 192 different samples. Once packed, cylinders were fitted with a diffuser and placed under a separatory funnel. Water was applied in 10 separate hydration events. Each hydration event consisted of $200 \mathrm{~mL}$ water being applied to the substratefilled cylinders at a rate of $\approx 3 \mathrm{~L} \cdot \mathrm{h}^{-1}$. As a result of hydrophobicity issues of some of the substrate components at $25 \% \mathrm{MC}$, water flow rate into the diffuser was slowed to prevent ponding on the substrate surface. The water was passed from the funnel, through the diffuser, onto the substrate, with a $2.5-\mathrm{cm}$ distance between the bottom of the diffuser and the surface of the substrate. As the water percolated through the substrate, it was either sorbed into or onto the substrate or passed through the substrate and was collected into a beaker below. Ponding on the substrate surface was controlled by keeping hydraulic head to a maximum of $2 \mathrm{~cm}$ by adjusting the stopcock at the base of the funnel. After the entire $200 \mathrm{~mL}$ of water had been applied and passed through the substrate-filled cylinders, equilibration was allowed until dripping ceased $(\approx 3 \mathrm{~min})$. Effluent water in the beakers was recorded and water retained by the substrate was calculated by subtracting leached water (effluent) from total water applied $(200 \mathrm{~mL})$. This procedure was repeated for a total of 10 hydrations for each sample.

Container capacity measurements. After the tenth hydration event was completed, cylinders were reweighed and any changes in volume resulting from shrinking or swelling were recorded. The cylinders were then placed into a Bucher funnel with holes as described in the North Carolina State University Porometer Manual (Fonteno and Harden, 1995). Samples were then saturated from below in a stepwise fashion at one-third intervals by adding water to the funnels between the cylinder and the funnel wall until water reached the top of the substrate. After saturating for $15 \mathrm{~min}$, the rubber stopper at the base of the funnel was removed and the water was allowed to drain for $30 \mathrm{~min}$. Samples were reweighed and new sample heights were again measured to observe any changes in volume. Samples were then dried at $105^{\circ} \mathrm{C}$ for $48 \mathrm{~h}$. Once dry, $\mathrm{MC}$ and total water retained were determined. 
Testing on commercial mixes. A final experiment was conducted on readily available commercially produced mixes for comparison with the substrate components tested. Three mixes were used: 1) Mix A was a commonly used commercial grower mix, composed of Canadian sphagnum peatmoss, processed pine bark, perlite, vermiculite, starter nutrients, WA, and dolomitic limestone; 2) Mix B was commercially available retail mix, composed of Canadian sphagnum peatmoss composted softwood bark, perlite, WA, and starter fertilizer; and 3) Mix $\mathrm{C}$ was a standard research and grower control mix, consisting of 3:1:1 peat:perlite:vermiculite (v:v:v), containing dolomitic lime, and WA. No additional WA was added to these mixes. The three mixes were moistened following the same procedures as described in Expt. 1, packed in the cylinders, and 10 hydration events were applied as also previously described. Similar to the substrate components in Expt. 1, the three mixes were tested at $50 \%$ and $25 \%$ MC. Three mixes $\times$ two IMs $\times$ four replications totaled 24 samples/treatments in this experiment.

Hydration efficiency. Data from the 10 hydration events were used to develop wettability curves for each of the samples tested in this experiment. These curves plot the volumetric water content of the sample after each hydration event. The container capacity (CC), which is the highest volumetric MC attained of each sample after saturation and drainage had occurred, was also plotted on the chart to show relationships between CC and sample water-holding after each hydration event. These wettability curves allow easy visualization of substrate hydration. Using the $\mathrm{CC}$ as the maximum hydration obtainable for that treatment, it is easy to compare CC with the curve to determine hydration efficiency of each individual sample.

Efficiency values. To provide numerical and statistical comparisons, each treatment had its hydration efficiency described with two values: 1) an initial hydration percentage (IHI) rating; and 2) a hydration efficiency value (HE). Initial hydration was the percentage of CC that was attained in a sample after one hydration event. The HE value was the number of hydration events required to bring the sample to CC. For example, if $\mathrm{CC}$ was reached at the first hydration event, an IHI of 1.0 and $\mathrm{HE}$ of 1 would be achieved. If the sample did not reach $\mathrm{CC}$ until the third hydration event, the HE value would be 3 and an IHI less than 1.0. If CC was not attained in the 10 hydration events, that treatment was given an " $x$ " in Table 1 to denote lack of achievement.

Statistics were determined on data using SAS Version 9.2 (SAS Institute, Cary, NC). A Tukey's honestly significant difference (HSD) test with alpha $=0.05$ was used to determine differences and similarities between the components at individual MCs and WA levels. A Tukey's HSD test with alpha $=0.05$ was also used to determine the differences in the HE values across all treatments in the experiment. Container capacity and IHI within each component at individual $\mathrm{MCs}$ had regression analysis conducted to determine the effect of the rates of WA on each component at each $\mathrm{MC}$. Both linear and quadratic regression was determined and significance was determined using $P$ values with significance ranging from $>0.001$ to 0.05 . An analysis of variance test was also conducted to test effects of WA and IM on CC and IHI among all components and within individual components.

\section{Results}

It should be noted that the initial MCs for these experiments $(50 \%$ and $25 \%)$ were determined by weight. This is the industry standard and essential when testing bulk materials with no specific container involved. However, the wettability curves are determined from volumetric water content to describe how much of the total substrate contains water. So the volumetric water contents on the curves at 0 hydration events are the initial moisture content values. Therefore, the initial moisture content of $50 \%$ by weight is actually

Table 1. Container capacity (CC), initial hydration percentage (IHI), and hydration efficiency index (HE) of six substrate components at two initial moisture contents (by weight) amended with either none (NWA), low (LWA), medium (MWA), or high (HWA) levels of wetting agents. ${ }^{2}$

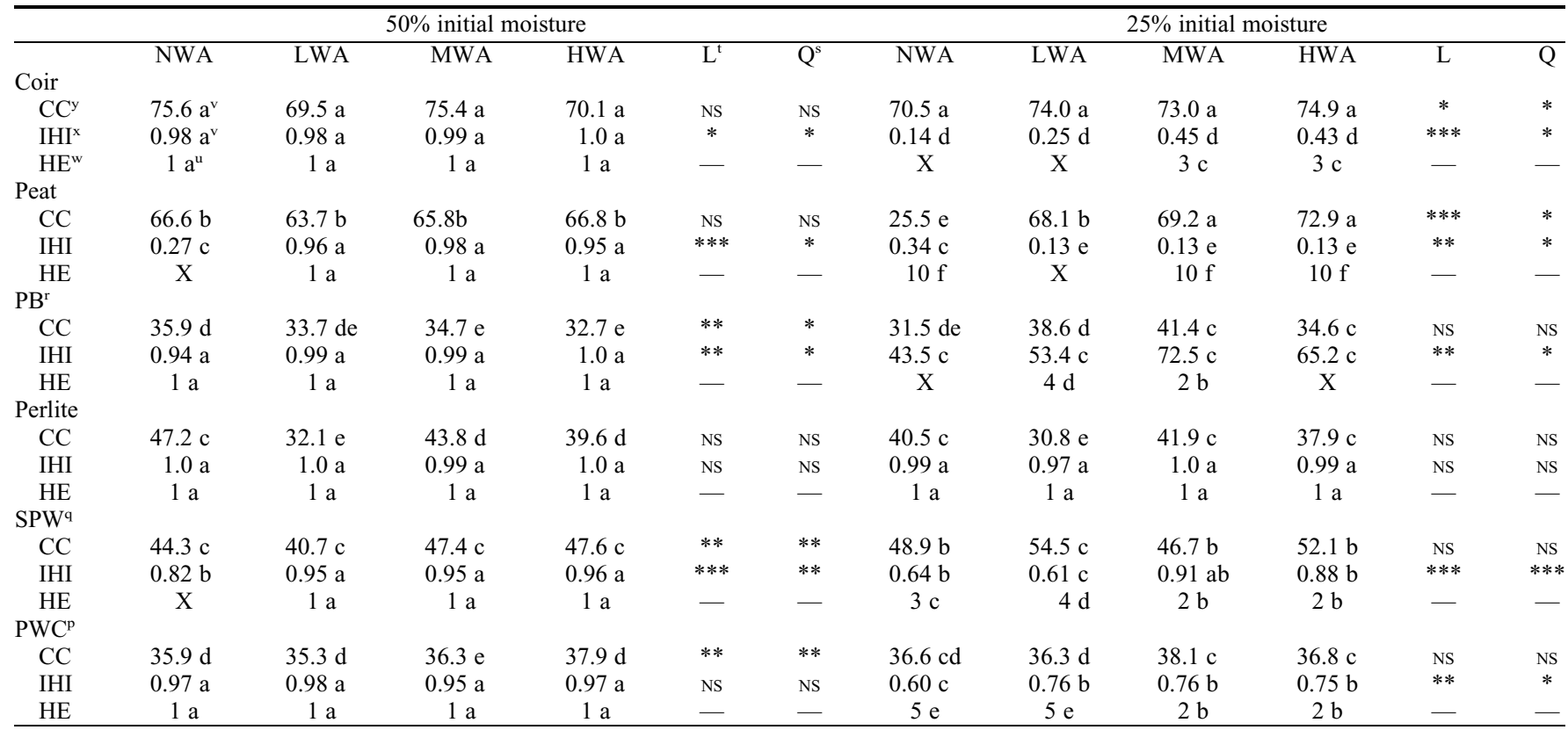

${ }^{\mathrm{z}}$ AquaGro ${ }^{\circledR}$-L (Aquatrols, Paulsboro, NJ) wetting agent at either 0 (none; NWA), 116 (low; LWA), 232 (medium; MWA), and 348 (high; HWA) mL·m ${ }^{-3}$ application rate, respectively.

${ }^{\mathrm{y}} \mathrm{CC}=$ maximum volumetric moisture content attained by sample.

${ }^{\mathrm{x}} \mathrm{IHI}=$ the percentage by volume of $\mathrm{CC}$ water that is sorbed in the substrate after the initial hydration event.

${ }^{\mathrm{w}} \mathrm{HE}=$ number of hydration events required to bring substrate treatments to $\mathrm{CC}$. " $\mathrm{X}$ " = did not reach CC.

${ }^{\mathrm{v}}$ Statistics using a Tukey honestly significant difference with alpha $=0.05$ are given down columns for a given wetting agent level and initial moisture.

"Statistics using a Tukey's honestly significant difference with alpha $=0.05$ are compared throughout the entire table.

${ }^{t}$ Linear regression significance test, $\mathrm{Ns}=$ nonsignificant, $* * * P \leq 0.001, * * P \leq 0.01 * P \leq 0.05$.

${ }^{\mathrm{s}} \mathrm{Quadratic}$ regression significance test. Ns $=$ nonsignificant, ${ }^{* * *} P \leq 0.001,{ }^{* *} P \leq 0.01 * P \leq 0.05$.

${ }^{\mathrm{r}} \mathrm{PB}=$ aged loblolly pine (Pinus taedea) bark.

${ }^{\mathrm{q}} \mathrm{SPW}=$ shredded loblolly pine wood hammermilled through 6.35 -mm screen.

${ }^{\mathrm{P} P W C}=$ pine wood chips made from hammermilled loblolly pine wood through a $6.35-\mathrm{mm}$ screen. 
$10 \%$ to $12 \%$ by volume for peat. For bark, the initial MCs ( $50 \%$ by weight) are $18 \%$ to $20 \%$ by volume. The differences are in the different densities for bark, peat, coir, perlite, etc. For clarity, we describe MCs determined by weight as IM and use the term $\mathrm{MC}$ to describe volumetric MC.

Coir. At 50\% IM, all WA levels, including 0 , reached maximum water content at the first hydration (Fig. 2A). Efficiency ratings were $\mathrm{HE}$ at 1 and an IHI near 1.0 (Table 1). However, at $25 \%$ IM, coir failed to reach $\mathrm{CC}$ in the 0 and low WA levels even after 10 hydrations (Fig. 2B). Coir samples with medium and high WA levels reached $\mathrm{CC}$ at three hydrations. The hydration efficiency for coir at 50\% IM was unaffected by WA levels. However, at 25\% IM, the medium to high WA levels and multiple hydration events were necessary to achieve maximum water uptake (Table 1). The addition of WA did not greatly affect the $\mathrm{CC}$ of coir but did play a significant role in improving coir's hydration efficiency at the lower $25 \%$ IM.

Peat. At 50\% IM, peat with $0 \mathrm{WA}$ did not reach $\mathrm{CC}$ after 10 hydrations (Fig. 3A). However, the low, medium, and high WA rates brought maximum hydration in one event. Similar CCs were attained in all WA treatments at $50 \%$ IM. Peat at $25 \%$ IM captured much less water at all WA levels than at 50\% IM (Fig. 3B). Apparently, strong hydrophobic forces prevented water absorption. At $0 \mathrm{WA}$, the CC value was severely decreased. This response was expected because peat has well documented hydrophobic forces at lower MCs (Michel et al., 2001). Although the WA treatments did improve water retention, the reduction in water capture was highly significant. The strong interaction between water capture and WA concentration was clearly evident.

Pine bark. Like with coir, at 50\% IM, pine bark (PB) achieved maximum hydration after one event at all WA levels (Fig. 4A). In fact, $\mathrm{PB}$ at $50 \%$ IM showed a slight negative linear relationship between CC and WA level, because an increase in WA level tended to lower the CC (Table 1). This is attributed to the WA lowering the surface tension of the water and allowing more drainage from the material with no observable hydrophobicity issues (Blok et al., 2008). At $25 \% \mathrm{IM}$, the $0 \mathrm{WA}$ samples never reached $\mathrm{CC}$, but higher WA levels improved hydration efficiency (Fig. 4B). This coincides with previous work that showed $\mathrm{PB}$ requiring an initial moisture content over 35\% and a WA treatment to achieve acceptable wetting (Airhart et al., 1980).

Perlite. Perlite was completely unaffected by any WA level or IM (Fig. 5A-B; Table 1). Perlite reached $\mathrm{CC}$ in one hydration event in every treatment, and there was no relationship between WA level and CC. This is likely the result of perlite being an inert mineral (Bunt, 1988) unlike the rest of the components in this
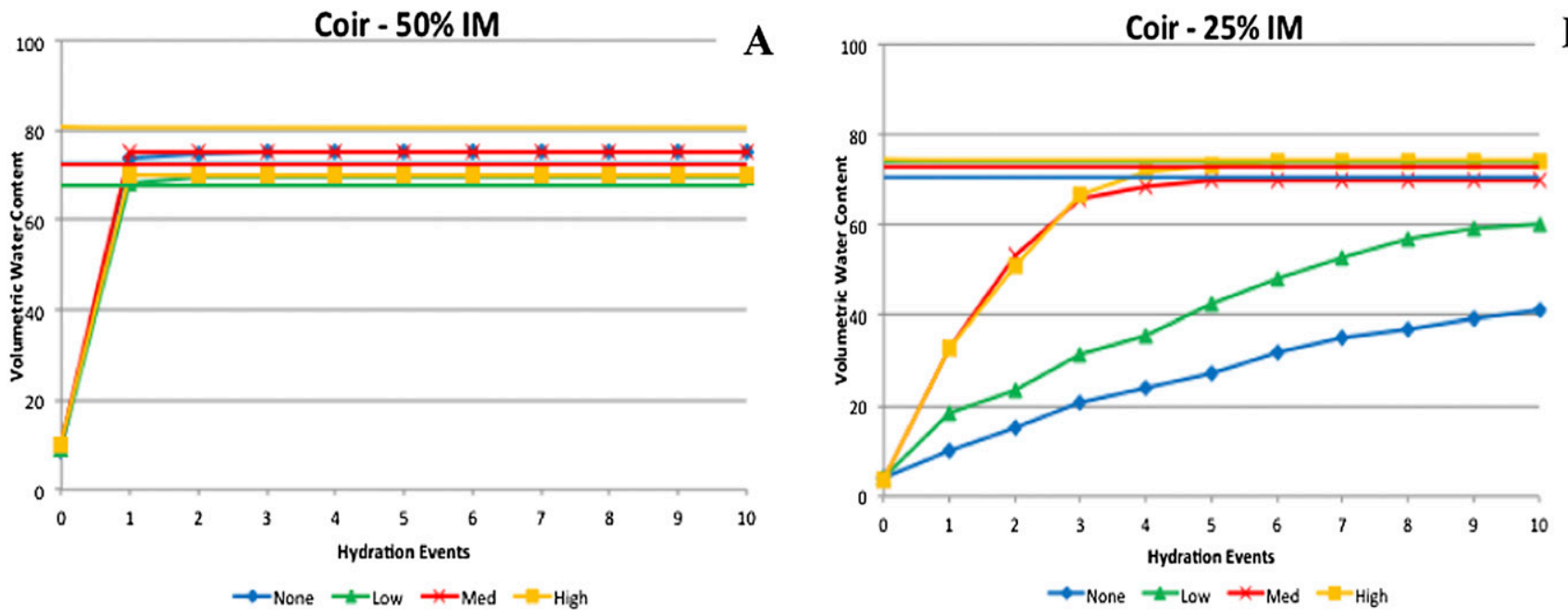

B

Fig. 2. Hydration efficiency curves for coir at four different wetting agent levels $\left(0 \mathrm{~mL} \cdot \mathrm{m}^{-3}=\right.$ none, $116 \mathrm{~mL} \cdot \mathrm{m}^{-3}=1 \mathrm{ow}, 232 \mathrm{~mL} \cdot \mathrm{m}^{-3}=\mathrm{medium}$, and $348 \mathrm{~mL} \cdot \mathrm{m}^{-3}=$ high) with container capacity represented as solid lines for (A) coconut coir at $50 \%$ initial moisture (IM) and (B) coconut coir at $25 \%$ IM.
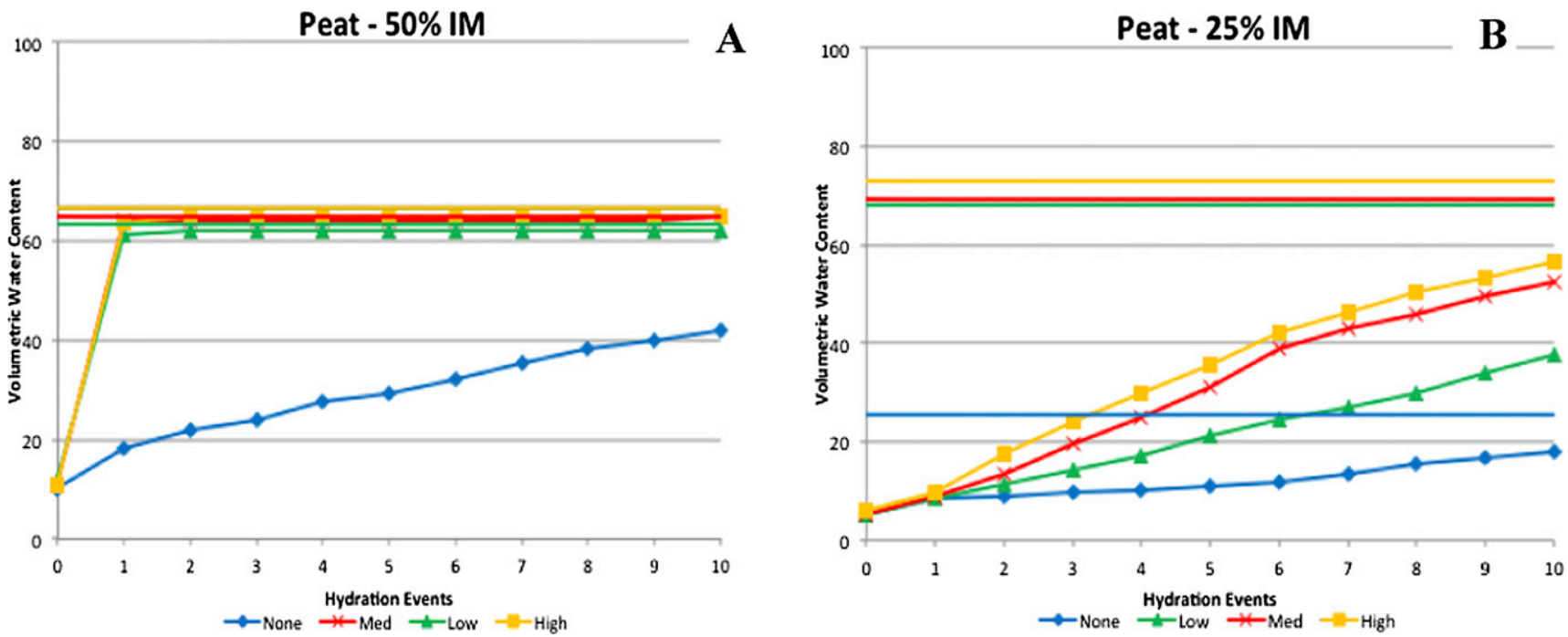

Fig. 3. Hydration efficiency curves for peatmoss at four different wetting agent levels $\left(0 \mathrm{~mL} \cdot \mathrm{m}^{-3}=\right.$ none, $116 \mathrm{~mL} \cdot \mathrm{m}^{-3}=10 \mathrm{w}, 232 \mathrm{~mL} \cdot \mathrm{m}^{-3}=\mathrm{medium}$, and 348 $\mathrm{mL} \cdot \mathrm{m}^{-3}=$ high) with container capacity represented as solid lines for (A) peatmoss at $50 \%$ initial moisture (IM) and (B) peatmoss at $25 \%$ IM. 

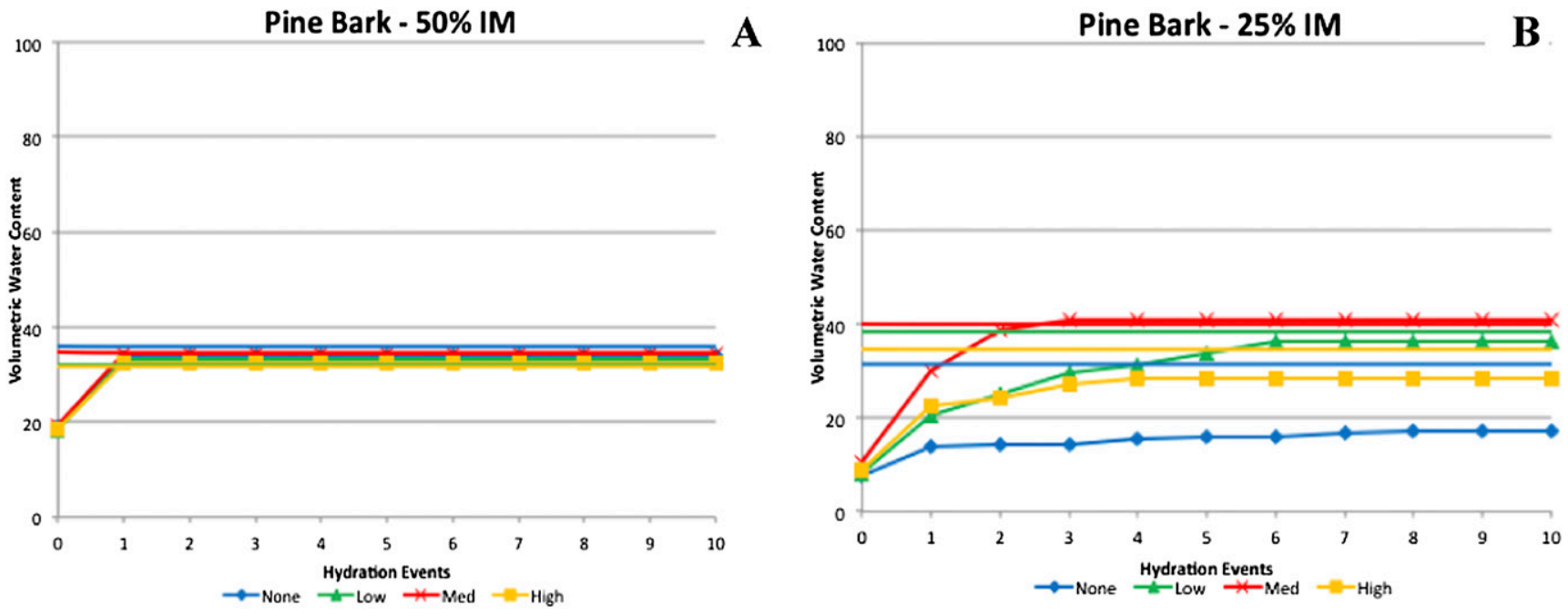

Fig. 4. Hydration efficiency curves for pine bark at four different wetting agent levels $\left(0 \mathrm{~mL} \cdot \mathrm{m}^{-3}=\right.$ none, $116 \mathrm{~mL} \cdot \mathrm{m}^{-3}=10 \mathrm{w}, 232 \mathrm{~mL} \cdot \mathrm{m}^{-3}=\mathrm{medium}$, and 348 $\mathrm{mL} \cdot \mathrm{m}^{-3}=$ high) with container capacity represented as solid lines for $(\mathbf{A})$ aged pine bark at $50 \%$ initial moisture (IM) and (B) aged pine bark at $25 \%$ IM.
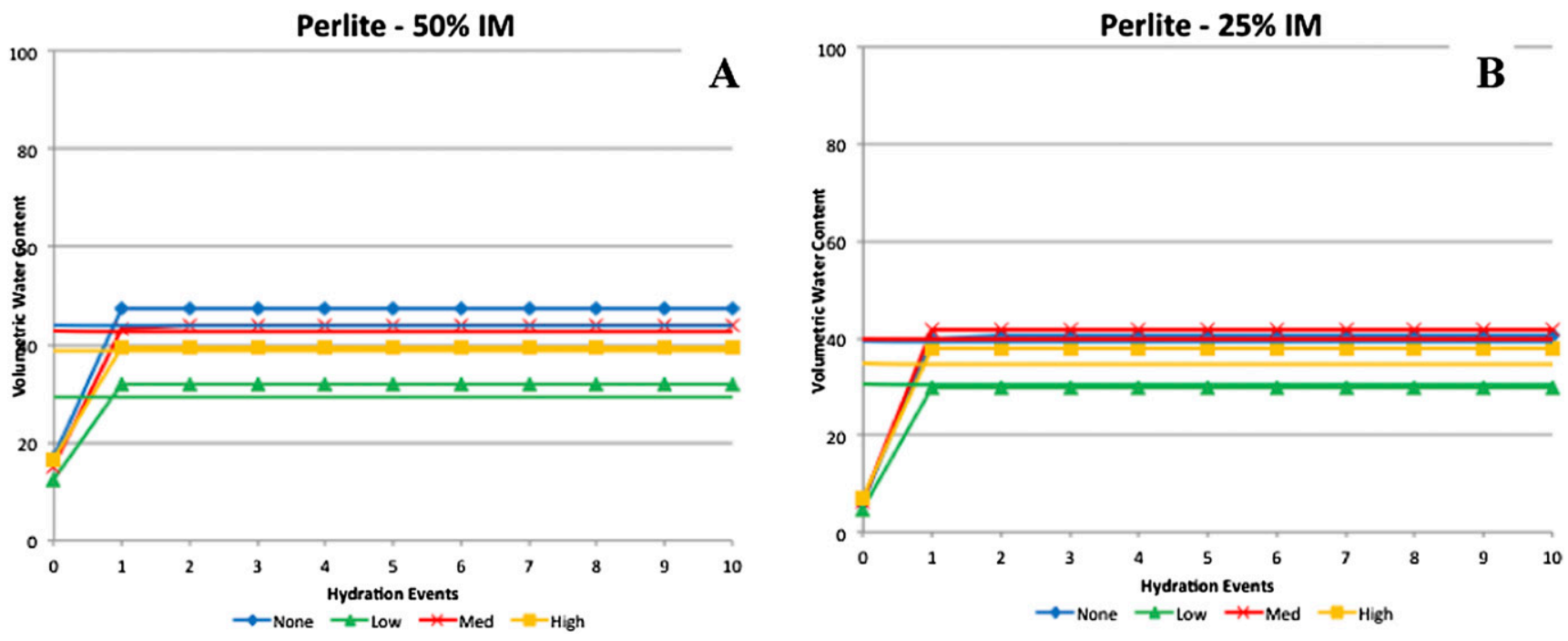

Fig. 5. Hydration efficiency curves for perlite at four different wetting agent levels $\left(0 \mathrm{~mL} \cdot \mathrm{m}^{-3}=\right.$ none, $116 \mathrm{~mL} \cdot \mathrm{m}^{-3}=10 \mathrm{w}, 232 \mathrm{~mL} \cdot \mathrm{m}^{-3}=\mathrm{medium}$, and $348 \mathrm{~mL} \cdot \mathrm{m}^{-3}=$ high) with container capacity represented as solid lines for (A) perlite at $50 \%$ initial moisture (IM) and (B) perlite at $25 \%$ IM.

experiment, which are biological in nature and have organic molecules influencing their hydration.

Shredded pine wood. At 50\% IM, all additions of WA, caused the SPW to reach CC in one hydration event (Fig. 6A). The 0 WA treatment had a high IHI $(0.82)$ but did not reach $\mathrm{CC}$ after 10 hydrations. However, at 25\% IM, the SPW hydrated to maximum levels in two to four events at all WA levels (Fig. 6B; Table 1). The HE values at $25 \%$ IM showed that the increased levels of WA caused the CC to be reached in fewer hydration events. Unlike more common materials, like coir, which is considered to be very easy to wet, and peat, which is the most commonly used component for greenhouse substrates, SPW required just three hydration events to reach CC at 25\% IM with no WA application. Lower MC and less WA are considered to increase hydrophobicity; however, an IHI value of 0.64 for SPW is significantly greater than that of both coir (14.2) and peat (34.3).
Pine wood chips. At 50\% IM, pine wood chips wet to maximum hydration at all WA levels (Fig. 7A; Table 1). At 25\% IM, the HE was $5,5,2$, and 2 with increasing WA levels, respectively, indicating increased efficiency with WA and that all treatments reached maximum hydration (Fig. 7B; Table 1). The PWC was manufactured to be more "blockular" (containing no fibers or splinters) and aggregate-like to increase aeration and drainage in a container substrate and therefore is more closely compared with perlite, which is the most commonly used component for this purpose (Nelson, 2012). Pine wood chips and perlite also share the same CC at 25\% IM at all WA levels except for the low WA rate, in which case PWC has a higher CC.

Commercial mixes. At 50\% IM, all three commercial mixes wet up to $\mathrm{CC}$ with the first hydration and maintained that level throughout the procedure (Fig. 8A). All three mixes have their own proprietary wetting agent in them and full wet-out was expected. However, at $25 \%$ IM, none of the mixes hydrated fully with the first hydration event (Fig. 8B). Mix B was closest to full hydration and reached $\mathrm{CC}$ in three hydration events. Mixes $\mathrm{A}$ and $\mathrm{C}$ did not reach container capacity in 10 hydrations. The curves for $\mathrm{A}$ and $\mathrm{C}$ did become asymptotic, indicating maximum hydration. However, neither reached their full potential for hydration. The level of hydrations at $25 \%$ IM were similar to the curves for peat at $25 \%$ IM. This is not surprising, because all three mixes contained from $30 \%$ to $60 \%$ peatmoss by volume.

\section{Discussion}

From these data we can determine that both WA and IM have effects on hydration efficiency of substrate components with IM having the greater effect on the IHI for all components. At $50 \%$ IM, the only material that did not hydrate was peat at $0 \mathrm{WA}$. At all levels with WA, every component at 50\% IM 

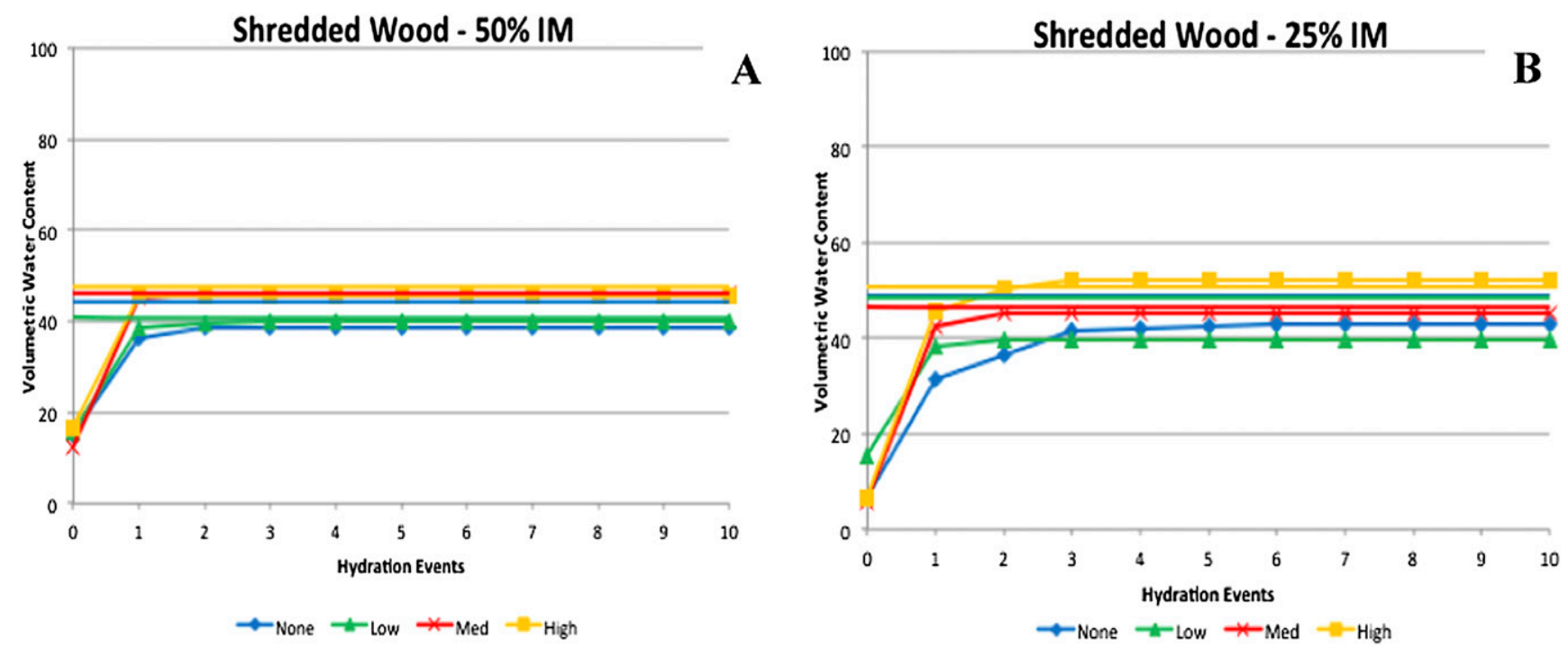

Fig. 6. Hydration efficiency curves for shredded wood at four different wetting agent levels $\left(0 \mathrm{~mL} \cdot \mathrm{m}^{-3}=\right.$ none, $116 \mathrm{~mL} \cdot \mathrm{m}^{-3}=10 \mathrm{w}, 232 \mathrm{~mL} \cdot \mathrm{m}^{-3}=\mathrm{medium}$, and 348 $\mathrm{mL} \cdot \mathrm{m}^{-3}=$ high) with container capacity represented as solid lines for $(\mathbf{A})$ shredded pine tree substrate at $50 \%$ initial moisture (IM) and (B) shredded pine wood substrate at $25 \%$ IM.
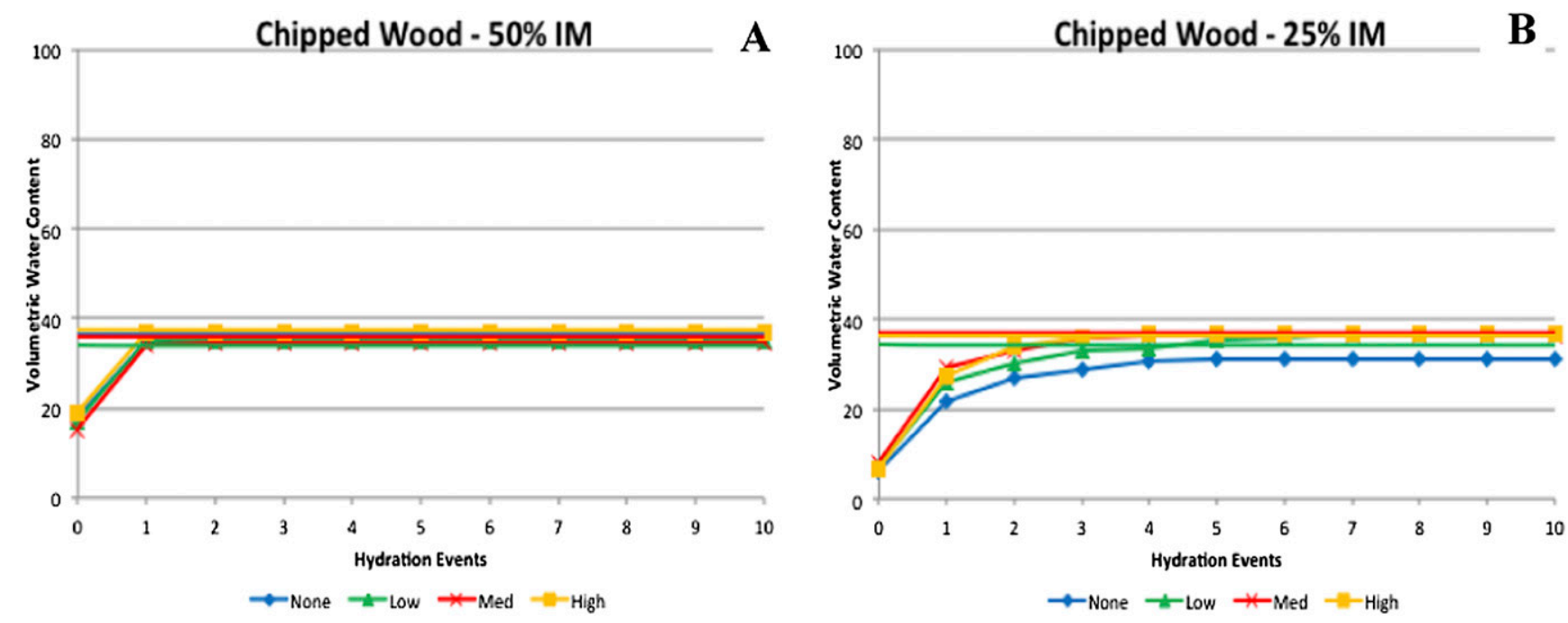

Fig. 7. Hydration efficiency curves for chipped wood at four different wetting agent levels $\left(0 \mathrm{~mL} \cdot \mathrm{m}^{-3}=\right.$ none, $116 \mathrm{~mL} \cdot \mathrm{m}^{-3}=10 \mathrm{w}, 232 \mathrm{~mL} \cdot \mathrm{m}^{-3}=\mathrm{medium}$, and $348 \mathrm{~mL} \cdot \mathrm{m}^{-3}=$ high) with container capacity represented as solid lines for (A) chipped pine tree substrate at $50 \%$ initial moisture (IM) and (B) chipped pine tree substrate at $25 \%$ IM.

has an IHI of 1.0, which denotes high hydration efficiency. Based on this, the $25 \%$ IM, a relatively low MC that has been associated with hydrophobicity issues in organic materials (Fonteno et al., 2013), is where most of the differences in hydration efficiency occurred. Coir has been shown to have a high wettability, much higher than peat (Abad et al., 2005), but at $25 \% \mathrm{IM}$, coir demonstrated more difficulty to wet properly (fully) than has been previously reported. At $25 \%$ IM, both the SPW and the PWC had the highest IHI and HE values compared with the other organic materials. Perlite, which achieved $\mathrm{CC}$ in one hydration regardless of IM and WA level, had no issues with wettability. This is likely a result of perlite being chemically inert (Hanna, 2005), having no organic functional groups, which can restrict water movement in organic materials (Ellerbrock et al.,
2005). However, perlite and PWC had very similar CCs across all treatments. Pine wood chips had an equal or higher CC than perlite in all treatments except for $50 \% \mathrm{IM}$ at 0 and medium WA treatments. Pine wood chips also had the same $\mathrm{CC}$ as pine bark in all treatments except for $50 \%$ IM at high WA, wherein the $\mathrm{CC}$ of PWC was $5.2 \%$ higher than that of PB.

Shredded pine wood had a higher $\mathrm{CC}$ than $\mathrm{PWC}, \mathrm{PB}$, and perlite in all treatments, except $50 \%$ IM at $0 \mathrm{WA}$, in which SPW was equal with perlite. As a result of the manufacturing process, SPW is a fibrous material with roughly frayed edges. These edges could have resulted in a higher percentage of fines (Table 2) and therefore a higher water-holding capacity (Handreck, 1983; Jackson et al., 2010; Richards et al., 1986). Fine-sized particles have much higher surface area than larger diameter particles. The greater surface area along with the larger micropore volume results in SPW having an increased CC. The geometry of the SPW allows it to not only have good aeration qualities like perlite and PWC, but the increased percent fines create a higher $\mathrm{CC}$, resulting in more peat-like properties.

As for the differences in treatments, WA level played a slight role in $\mathrm{CC}$ in $\mathrm{PB}$ and SPW at $50 \%$ IM as well as coir at $25 \%$ IM. Wetting agent also played a significant role in peat at $25 \%$ IM, because the presence of WA helped to mitigate the hydrophobicity issues. Initial hydration percentage was significant at all WA levels across both IMs except for perlite, which had no wettability issues and $50 \%$ IM in PWC. Across all experiments, IM had a significant effect on IHI, whereas WA did not, and $\mathrm{CC}$ was unaffected by either.

Examining the results of the commercial substrates, the effects of IM are present. All 

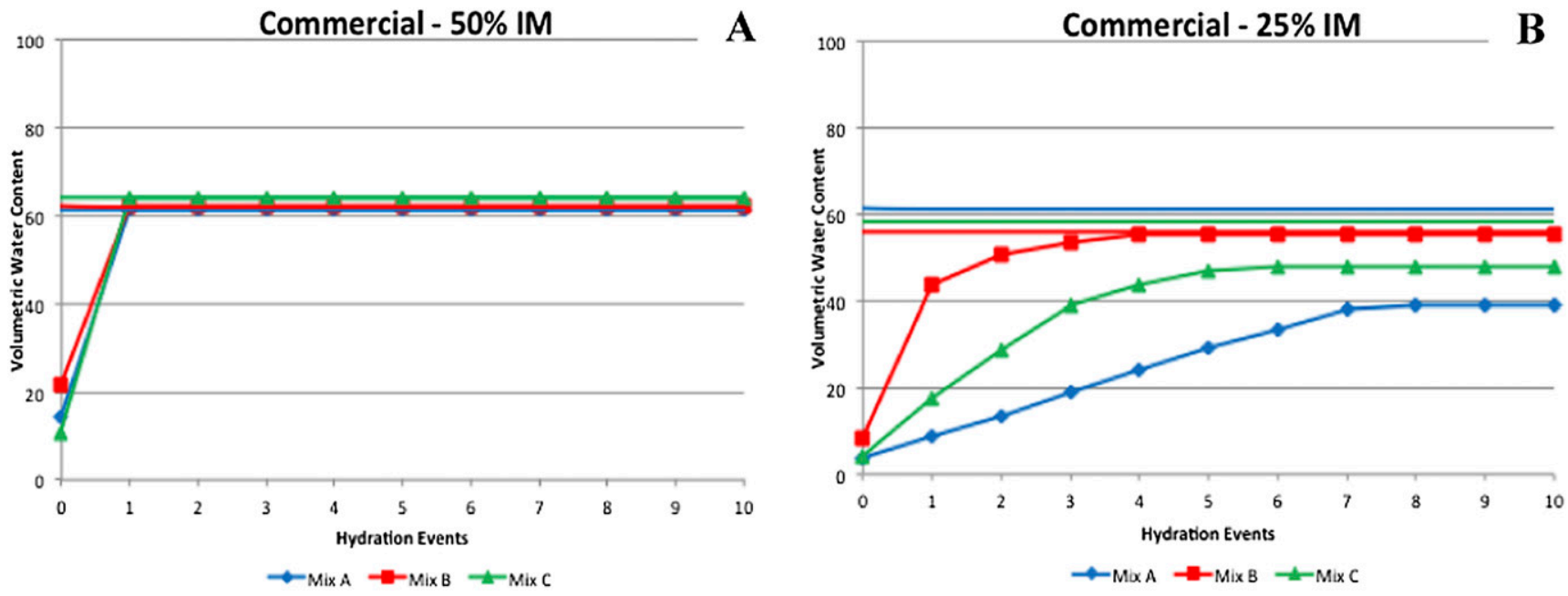

Fig. 8. Hydration efficiency curves for three commercial substrate mixes (Mix A, Mix B, Mix C) at (A) 50\% initial moisture (IM), and (B) at 25\% IM.

Table 2. Particle size distribution of six traditional and alternative greenhouse substrate components. ${ }^{\mathrm{z}}$

\begin{tabular}{lcccrrr}
\hline \multicolumn{5}{c}{} & \multicolumn{5}{c}{ Substrate component } \\
\cline { 2 - 6 } & Coir & Peat & Pine bark & Perlite & SPW $^{\mathrm{y}}$ & PWC $^{\mathrm{x}}$ \\
X-large $^{\mathrm{w}}$ & $0.2 \mathrm{c}^{\mathrm{v}, \mathrm{u}}$ & $2.7 \mathrm{~b}$ & $18.2 \mathrm{a}$ & $0.2 \mathrm{c}$ & $0.0 \mathrm{e}$ & $0.0 \mathrm{e}$ \\
Large $^{\mathrm{t}}$ & $5.6 \mathrm{e}$ & $18.1 \mathrm{~d}$ & $35.0 \mathrm{c}$ & $45.2 \mathrm{~b}$ & $34.7 \mathrm{c}$ & $66.1 \mathrm{a}$ \\
Medium $^{\mathrm{s}}$ & $30.2 \mathrm{~b}$ & $27.6 \mathrm{bc}$ & $25.3 \mathrm{bc}$ & $21.4 \mathrm{c}$ & $45.6 \mathrm{a}$ & $27.1 \mathrm{bc}$ \\
Fines $^{\mathrm{r}}$ & $64.0 \mathrm{a}$ & $51.6 \mathrm{~b}$ & $21.5 \mathrm{~d}$ & $33.2 \mathrm{c}$ & $19.7 \mathrm{~d}$ & $6.8 \mathrm{e}$ \\
\hline
\end{tabular}

zParticle size distribution determined by sieving through 11 sieves for $5 \mathrm{~min}$ in a shaker.

${ }^{\mathrm{y}} \mathrm{SPW}=$ shredded pine wood produced by hammermilling shredded loblolly pine (Pinus taeda) trees.

${ }^{\mathrm{x}} \mathrm{PWC}=$ pine wood chips produced by hammermilling chipped loblolly pine trees.

${ }^{\mathrm{w}} \mathrm{X}$-large particles are greater than $6.3 \mathrm{~mm}$ in diameter.

${ }^{v}$ Values are means of percentages of total sample.

"Statistics are determined across rows using a Tukey's honestly significant difference to determine differences and similarities among different components within a particle size fraction.

'Large particles are less than $6.3 \mathrm{~mm}$ and greater than $2.0 \mathrm{~mm}$ in diameter.

${ }^{\mathrm{s}}$ Medium particles are less than $2.0 \mathrm{~mm}$ and greater than $0.5 \mathrm{~mm}$ in diameter.

${ }^{\mathrm{r}}$ Fine particles are less than $0.5 \mathrm{~mm}$ in diameter.

three substrates had an $\mathrm{HE}$ value of 1 at $50 \%$ IM (Fig. 7A). At 25\% IM, each substrate took longer (more irrigation events) to achieve $\mathrm{CC}$ (Fig. 7B). This reduced ability to absorb water at the lower initial MC was similar to that of peat, coir, and bark, whereas the two wood components were less affected.

Comparing HE values across all treatments, there were slight effects among WA levels and a strong effect of pre-irrigation IMs. Both WA level and IM had a strong effect on hydration efficiency, but initial moisture was the predominant effect. This points out how critical pre-irrigation $\mathrm{MC}$ is to substrate hydration efficiency. MC should be more fully explored as it relates to hydration efficiency. This work also demonstrates the increased importance of initial watering to the overall hydration efficiency of newly transplanted crops in horticultural substrates.

\section{Literature Cited}

Abad, M., F. Frones, C. Carrion, and V. Noguero. 2005. Physical properties of various coconut coir dusts compared to peat. HortScience 40:21382144.

Airhart, D.L., N.J. Naturella, and F.A. Pokorny. 1980. Wetting a milled pine bark medium with surfactants. For. Prod. J. 30:30-33.

Beardsell, D.V. and D.G. Nichols. 1982. Wetting properties of dried-out nursery container media. Sci. Hort. 17:49-59.
Blok, C., C. de Kreij, R. Baas, and G. Weaver. 2008. Analytical methods used in soilless cultivation, p. 245-289. In: Raviv, M. and J.H. Lieth (eds.). Soilless culture. Elsevier, London, UK.

Bunt, A.C. 1988. Media and mixes for containergrown plants. 2nd Ed. Unwin Hyman Ltd., London, UK.

Dekker, L.W. and C.J. Ritsema. 1994. How water moves in a water repellent sandy soil-1. Potential and actual water repellency. Water Resour. Res. 30:2507-2517.

Dekker, L.W., C.J. Ritsema, and K. Oostindie. 2000a. Wettability and wetting rate of sphagnum peat and turf on dune sand effected by surfactant treatments, p. 566-574. In: Rochefort, L. and J.-Y. Daigle (eds.). Proc. 11th Int. Peat Cong. 6-12 Aug. 2000, Quebec, Canada.

Dekker, L.W. and C.J. Ritsema. 2000b. Wetting patterns and moisture variability in water repellant Dutch soils. J. Hydrol. (Amst.) 232: $148-164$.

de Jonge, L.W., O.H. Jacobsen, and P. Moldrup. 1999. Soil water repellency: Effects of water content, temperature, and particle size. Soil Sci. Soc. Amer. J. 63:437-442.

Ellerbrock, R.H., H.H. Gerke, J. Bachmann, and M.O. Goebel. 2005. Composition of organic matter fractions for explaining wettability of three forest soils. Soil Sci. Soc. Amer. J. 69:5766.

Fonteno, W.C., J.S. Fields, and B.E. Jackson. 2013. A pragmatic approach to wettability and hydration of horticultural substrates. Acta Hort. 1013:139-146.
Fonteno, W.C. and C.T. Harden. 1995. North Carolina State University horticultural substrates lab manual. North Carolina State University, Raleigh, NC.

Gautam, R. and N. Ashwath. 2012. Hydrophobicity of 43 potting media: Its implications for raising seedlings in revegetation programs. J. Hyrol 430-431:111-117.

Handreck, K.A. 1983. Particle size and the physical properties of growing media for containers. Commun. Soil Sci. Plant Anal. 14:209-222.

Hanna, H.Y. 2005. Properly recycled perlite saves money, does not reduce greenhouse tomato yield, and can be re-used for many years. HortTechnology 15:342-345.

Jackson, B.E. and W.C. Fonteno. 2013. New media components-Are they worth their weight in dirt? OFA Bulletin 938:14-18.

Jackson, B.E., R.D. Wright, and M.C. Barnes. 2010. Methods of constructing a pine tree substrate from various wood particle sizes, organic amendments, and sand for desired physical properties. HortScience 45:103-112.

Letey, J. 1969. Measurement of contact angle, water drop penetration time, and critical surface tension, p. 43-47. In: DeBano, L.F. and J. Letey (eds.). Proc. Symp. Water-repellent Soils.

Letey, J., J. Osborn, and R.E. Pelishek. 1962. Measurement of liquid-solid contact angles in soil and sands. Soil Sci. 93:149-153.

Michel, J.C. 2009. Influence of clay addition on physical properties and wettability of peat growing media. HortScience 44:1694-1697.

Michel, J.C., L.M. Riviere, and M.N. BellonFontaine. 2001. Measurement of wettability of organic materials in relation to water content by the capillary rise method. European J. Soil. Sci. 52:459-467.

Nelson, P.V. 2012. Greenhouse operation and management. 7th Ed. Pearson, Upper Saddle River, NJ.

Plaut, Z., N. Zielsin, and Y. Arnon. 1973. The influence of moisture regime on greenhouse rose production in various growth media. Sci. Hort. 1:239-250.

Richards, D., M. Lane, and D.V. Beardsell. 1986. The influence of particle-size distribution in pinebark:sand:brown coal potting mixes on water supply, aeration, and plant growth. Sci. Hort. 29:1-14.

Valat, B., C. Jouany, and L.M. Riviere. 1991. Characterization of the wetting properties of air dried peats and composts. Soil Sci. 152:100-107. 